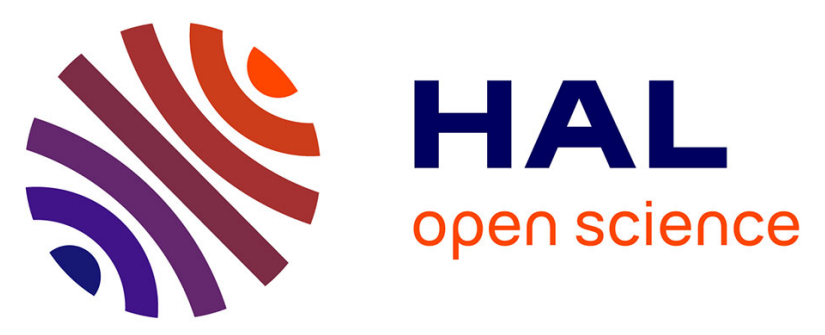

\title{
Study on Spatial Distribution Characters of Rubber Yield and Soil Nutrients in Guangba Farm of Hainai Province
}

Bei Cui, Wenjiang Huang, Huichun Ye, Qimin Cao

\section{To cite this version:}

Bei Cui, Wenjiang Huang, Huichun Ye, Qimin Cao. Study on Spatial Distribution Characters of Rubber Yield and Soil Nutrients in Guangba Farm of Hainai Province. 11th International Conference on Computer and Computing Technologies in Agriculture (CCTA), Aug 2017, Jilin, China. pp.283291, 10.1007/978-3-030-06179-1_29 . hal-02111542

\section{HAL Id: hal-02111542 \\ https://hal.inria.fr/hal-02111542}

Submitted on 26 Apr 2019

HAL is a multi-disciplinary open access archive for the deposit and dissemination of scientific research documents, whether they are published or not. The documents may come from teaching and research institutions in France or abroad, or from public or private research centers.
L'archive ouverte pluridisciplinaire HAL, est destinée au dépôt et à la diffusion de documents scientifiques de niveau recherche, publiés ou non, émanant des établissements d'enseignement et de recherche français ou étrangers, des laboratoires publics ou privés. 


\title{
Study on Spatial Distribution Characters of Rubber Yield and Soil Nutrients in Guangba Farm of Hainai
}

\author{
Province \\ Bei Cui ${ }^{1,2(\varpi)}$, Wenjiang Huang ${ }^{1,2}$, Huichun $\mathrm{Ye}^{1,2}$, Qimin $\mathrm{Cao}^{3}$ \\ ${ }^{1}$ Institute of Remote Sensing and Digital Earth, Chinese Academy of Sciences, \\ Beijing100094, PR China \\ ${ }^{2}$ Key Laboratory of Earth Observation, Hainan Province, Sanya 572029, PR China \\ \{cuibei, huangwj, yehc\} \& radi.ac.cn \\ ${ }^{3}$ Hainan State Farms academy of sciences, Hainan Province, Haikou 570100, PR China \\ 271093491 @q. com
}

\begin{abstract}
Studying the spatial distribution characters of rubber yield and soil nutrients and the rule of spatial variability are important for suitable fertilization strategy in rubber plantation. This paper selected Hongquan Branch, Guangba Branch and Gongai Branch of Guangba Farm in Hainan province as study area and total of 327 samples were selected in the rubber plantation. The spatial distribution characters of rubber yield and five soil nutrients, including organic matter (OM), total nitrogen (TN), available phosphorus (AP), available potassium (AK), exchangeable calcium (Ga), were studied using traditional analysis method and geo-statistics analysis method. The results showed that: (1) The average value of rubber yield was $3.55 \mathrm{~kg} / \mathrm{hm}^{2}$ with moderate spatial variability and the average values of OM, N, P, K and Ga were $11.65 \mathrm{~g} / \mathrm{kg}, 0.07 \%, 16.23 \mathrm{mg} / \mathrm{kg}, 49.65 \mathrm{mg} / \mathrm{kg}$ and 84.44 $\mathrm{mg} / \mathrm{kg}$, respectively. Soil OM, TN, AK and Ga had moderate spatial variability but AP had strong spatial variability. (2) Rubber yield and soil total nitrogen $(\mathrm{N})$ nutrient had strong spatial dependence; soil OM, AP, AK and Ga had moderate spatial dependence. (3) Based on the previous reports of normal range of soil nutrients, soil OM and TN nutrient content were very low in the studied rubber plantation of Guangba Farm. Therefore, more nitrogen fertilizer should be applied in the rubber plantation in future.
\end{abstract}

Keywords: spatial distribution characters · rubber yield · soil nutrients · Guangba Farm

\section{Introduction}

Rubber plantation soil is an important resource of nutrient for rubber tree, the fertility condition is closely related to rubber growth and production. However, due to the influence of complex terrain, different cultivation methods and many factors in the process of soil-forming, the spatial distribution pattern of soil nutrient in rubber plantation is not homogeneous but highly heterogeneous, which made 
the large spatial variability of rubber yield. Therefore, studying the spatial distribution characters of rubber yield and soil nutrients and the rule of spatial variability are important to formulate a suitable fertilization strategy in rubber plantation.

Recently, many researches about the spatial variability of soil nutrients of rubber plantation could be found in the literatures. Yang et al. [1] pointed out that both soil total potassium and available potassium had moderate spatial dependence in rubber plantation of Danzhou city. Yang [2] showed that soil available potassium (AK) and total potassium (TK) had strong spatial dependence; soil available nitrogen (AN), total nitrogen (TN), available phosphorus (AP), total phosphorus (TP), $\mathrm{pH}$ and organic matter (OM) had moderate spatial dependence in Lanyang Town rubber plantation. Qin $e t$ al. [3] showed that both soil total phosphorus and available phosphorus at the depth of $0-20 \mathrm{~cm}$ and 20-40cm had moderate spatial dependence in rubber plantation of Qiongzhong County. Li et al. [4] found that $\mathrm{OM}, \mathrm{TN}$, available $\mathrm{K}(\mathrm{AK})$ and $\mathrm{pH}$ were at normal range but soil available $\mathrm{P}$ was below normal level in Dongfeng Farm of Yunnan province. In addition, all parameters of soil OM, TN, AK and $\mathrm{pH}$ had strong spatial dependence, indicting the spatial variability of these soil nutrients were mainly caused by structural factors, such as climate, terrain, agrotype and so on. Gao et al. [5] pointed out that soil available nitrogen, available phosphorus and available potassium had strong or moderate spatial dependence in rubber plantation of Ledong, Hainan. We can find from above researches that the spatial distribution characters of soil nutrients were different in different rubber plantations, even at the same site but at different time. So, the spatial distribution characters of soil nutrients should be studied for the specific research areas.

In addition, rubber yield is deeply affected by rubber plantation soil nutrients. Li et al. [6] pointed out the soil nutrients, such as nitrogen, potassium, phosphorus, can affect the rubber formation and latex flow through influencing the photosynthesis. So, the spatial heterogeneity of rubber plantation soil nutrients maybe lead to the spatial variability of rubber yield. Although many positive results of crop yield and soil nutrients have been reported in the literatures [7, 8, 9, 10], there has rarely studies about the spatial variability characters of rubber yield and its relationship with soil nutrients so far.

In this study, rubber yield and five soil nutrients were studied in Hongquan Branch, Guangba Branch, Gongai Branch of Guangba Farm. The objectives of this study were: (i) to assess the condition of rubber yield and soil fertility in the rubber plantation of Guangba Farm; and (ii) to understand the spatial variability characters of rubber yield and soil nutrients using Geo-statists method and the relationship between rubber yield and soil nutrients.

\section{Materials and Methods}

\subsection{Study area}

The study area is Hongquan Branch, Guangba Branch, Gongai Branch of Guangba Farm, which is located in the Dongfang city of Hainan province. This site has a mean annual rainfall of $1600 \mathrm{~mm}$ and a mean annual temperature of $24.2{ }^{\circ} \mathrm{C}$. The terrain slopes gently with slopes of about 10 degrees and elevations of 120 m-160 m above the sea level. Rubber is one of the main economic forests planted in Guangba Farm with more than $3333 \mathrm{hm}^{2}$ in area. We conducted field surveys of rubber plantations and obtained rubber yield and corresponding soil nutrient parameters data in about 327 rubber stands. The location of Guangba Farm and field survey samples are shown in Fig. 1. 


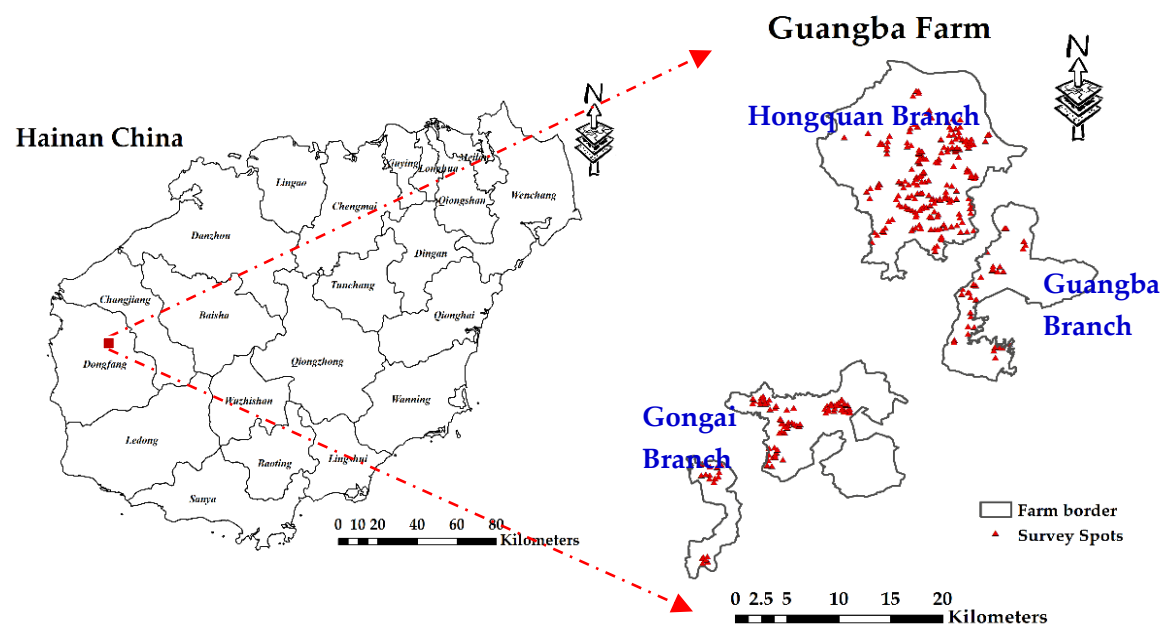

Fig.1. The location of study area and field survey samples

\subsection{Data collection}

In this study, a total of 327 rubber stands were randomly selected in the rubber plantation of Hongquan Branch, Guangba Branch, Gongai Branch of Guangba Farm in 2010. The detailed records of latex yield per time of each rubber stand were recorded, and the annual rubber yield at each rubber stand was calculated.

The corresponding 327 soil samples at the depth of $0-20 \mathrm{~cm}$ in the rubber plantation were collected in 2010. For each rubber stand, five representative soil-sampling sites were randomly selected within a $10 \mathrm{~m}$ radius near the center of site. Then they were mixed to form one composite sample representing this site. The location of each site was recorded by a DGPS receiver with accuracy of $0.2 \mathrm{~m}$. Soil organic matter $(\mathrm{OM})$ was calculated by using oil bath- $\mathrm{K}_{2} \mathrm{Cr}_{2} \mathrm{O}_{7}$ titration method [11]. Soil total nitrogen (TN) was calculated by using semi-micro Kjeldahl method, soil available phosphorus (AP) was calculated by using Ammonium-hydrochloride method, soil available potassium (AK) was calculated by using $\mathrm{NH}_{4} \mathrm{OAc}$ extraction- flame photometer method, and soil exchangeable calcium (Ga) was calculated by using $1 \mathrm{~mol} / \mathrm{L}$ ammonium acetate exchange atomic absorption spectrophotometry [12].

\subsection{Analyses method and software}

The conventional statistics for raw experimental data was conducted using SPSS 22 software for Windows (SPSSInc., Chicago, IL, USA) with mean, maximum, minimum, standard deviation (SD), kurtosis, skewness and coefficient of variation $(\mathrm{CV})$. Kurtosis and skewness values were used to test whether the raw data follow normal distribution. If the raw data did not follow normal distribution, $3 \delta$ Method [13], logarithmic or power transformations should be applied to meet the hypothesis of geo-statistical analysis. Coefficient of variation (CV) was identified as a basic parameter for spatial variability. If $\mathrm{CV}<10 \%$, it means weak spatial variability; if $10 \%<\mathrm{CV}<100 \%$, it means moderate spatial variability; if $\mathrm{CV}>100 \%$, it means strong spatial variability.

The semi-variogram model was used to indicate spatial structure and the degree of spatial dependence of rubber yield and five soil nutrients. The semi-variogram model is described usually by five main parameters, i.e. nugget, partial sill, sill, range and Nugget/Sill [14]. Nugget means the spatial variation of variable was led by random factors and partial sill means the spatial variation was led by 
structure factors such as soil texture, crop variety and etc. Sill is the sum of nugget and partial sill, which means the total spatial variation of variable. The range means the max distance between two locations with spatial dependence. The last but the most important parameter is the value of Nugget/Sill ratio, which can directly indicate the degree of spatial dependence and the reason led to spatial variation by random or structure factors. If the value of Nugget/Sill ratio $<25 \%$, it means strong spatial dependence and structure factors as dominant variation reason; if $25 \%<$ Nugget/Sill ratio $<75 \%$, it means moderate spatial dependence; if Nugget/Sill ratio $>75 \%$, it means weak spatial dependence and random factors as dominant variation reason. The best fit theoretical semi-variogram model for different variables were simulated and the fitting accuracy were evaluated according to $\mathrm{R}^{2}$ indicators. All above analysis were conducted using GS 10+ software.

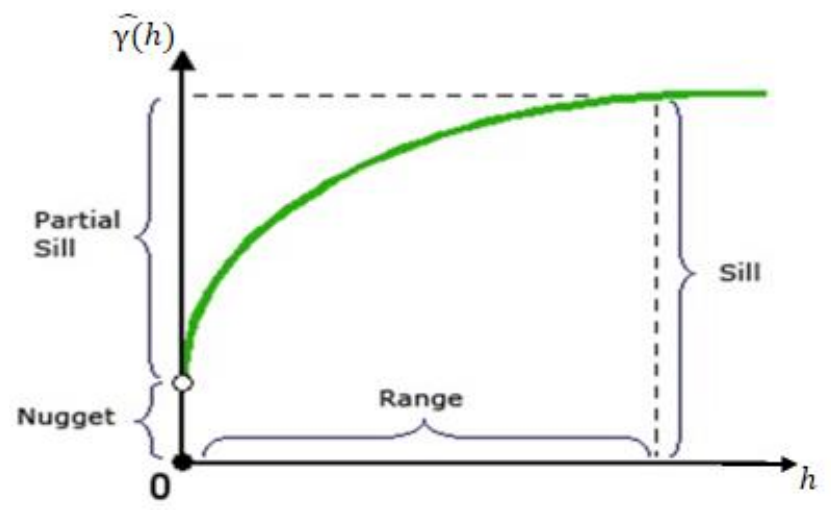

Fig.2. Parameters of semi-variogram model [14]

\section{Results}

\subsection{Analysis rubber yield and soil nutrients}

The basic statistical information of rubber yield and five kinds of soil nutrients, including soil organic matter $(\mathrm{OM})$, total nitrogen $(\mathrm{N})$, available phosphorus $(\mathrm{P})$, available potassium $(\mathrm{K})$ and exchangeable calcium (Ga), were shown in Table 1. For yield, OM, N, K and Ga, the coefficients of variation varied between $42.9 \%$ and $86.5 \%$, which were greater than $10 \%$ and less than $100 \%$, indicating all these parameters had moderate variability. However, the coefficient of variation for P reached up to $173.3 \%$, which meant the variability of $\mathrm{P}$ was strong.

Furthermore, because Geo-statistics analysis require all data studied should be normally distributed, all outliers should firstly be checked before the testing of data normal distribution using the $3 \delta$ Method. If the data are still non-normality distribution after correction outliers, data transform (log, square-root and etc.) should be used to ensure that the data obey the normal distribution. In this study, logarithm transition were used for the parameters of yield, P, K and Ga. Through the above-mentioned processing, the values of skewness and kurtosis of all data used in this study were very small as shown in Table 1, indicating that they were all normally distribution.

Table 1. The basic statistical information of rubber yield and five soil nutrients

\begin{tabular}{lllllllll}
\hline & $\mathrm{N}$ & Min & Max & Mean & SD & CV (\%) & Skewness & Kurtosis \\
\hline Yield $\left(\mathrm{kg} / \mathrm{hm}^{2}\right)$ & 327 & 1.33 & 8.80 & 3.55 & 26.03 & $48.8 \%$ & 0.34 & -0.64 \\
OM $(\mathrm{g} / \mathrm{kg})$ & 327 & 0.50 & 29.10 & 11.65 & 5.72 & $49.1 \%$ & 0.49 & 0.06 \\
TN $(\%)$ & 327 & 0.01 & 0.16 & 0.07 & 0.03 & $42.9 \%$ & 0.81 & 0.46
\end{tabular}




\begin{tabular}{lllllllll}
$\mathrm{AP}(\mathrm{mg} / \mathrm{kg})$ & 327 & 1.10 & 165.70 & 16.23 & 28.12 & $173.3 \%$ & 0.76 & 0.88 \\
$\mathrm{AK}(\mathrm{mg} / \mathrm{kg})$ & 327 & 12.00 & 121.00 & 49.65 & 22.58 & $45.5 \%$ & -0.07 & -0.14 \\
$\mathrm{Ga}(\mathrm{mg} / \mathrm{kg})$ & 327 & 5.30 & 345.60 & 84.44 & 73.07 & $86.5 \%$ & -0.19 & -0.45 \\
\hline
\end{tabular}

Soil organic matter $(\mathrm{OM})$; total nitrogen $(\mathrm{TN})$; available phosphorus (AP); available potassium (AK); exchangeable calcium $(\mathrm{Ga})$

\subsection{Analysis spatial distribution characters of rubber yield and soil nutrients}

To understand the spatial structure and distribution of rubber yield within the farm is very importance to understand the difference of production capacity among different rubber stands and to make specific fertilizer application strategies according to different levels of yield capacity regions.

In this study, the best fit theoretical semi-variogram model and parameters for rubber yield and five soil nutrients were given in Table 2 and Fig. 3. The Exponential model was found to be the best fit model for rubber yield, and the range for yield was $3.34 \mathrm{~km}$. Nugget: sill ratio values for rubber yield was $15.30 \%$, which was less than $25 \%$, indicating strong spatial dependence mainly resulted from structural factors such as rubber cultivar, terrain, climate and so on. The best fit model for the five soil nutrients was Exponential model. The values of $\mathrm{C}_{0} /\left(\mathrm{C}_{0}+\mathrm{C}\right)$ for $\mathrm{OM}, \mathrm{AP}, \mathrm{AK}$ and $\mathrm{Ga}$ were in the range of $25 \%-75 \%$, but for $\mathrm{N}$ was less than $25 \%$, which indicated that soil OM, AP, AK and Ga had moderate spatial dependence and soil $\mathrm{TN}$ has strong spatial dependence. The $\mathrm{R}^{2}$ for all parameters studied were in the range of $0.54-0.85$, indicating that the selected models can preferably reflect the spatial distribution characters of these parameters.

Table 2. Best fit theoretical semi-variogram model and parameters for rubber yield and soil nutrients

\begin{tabular}{lllllll}
\hline & Model & Nugget & Sill & $\mathrm{C}_{0} /\left(\mathrm{C}_{0}+\mathrm{C}\right)$ & Range $(\mathrm{km})$ & $\mathrm{R}^{2}$ \\
\hline Yield $\left(\mathrm{kg} / \mathrm{hm}^{2}\right)$ & Exponential & 0.03 & 0.17 & $15.30 \%$ & 3.34 & 0.54 \\
$\mathrm{OM}(\mathrm{g} / \mathrm{kg})$ & Exponential & 24.100 & 50.2100 & $48.0 \%$ & 71.47 & 0.73 \\
$\mathrm{TN}(\%)$ & Exponential & 0.0001 & 0.0008 & $14.2 \%$ & 3.01 & 0.71 \\
$\mathrm{AP}(\mathrm{mg} / \mathrm{kg})$ & Exponential & 0.5610 & 1.5020 & $37.4 \%$ & 219.74 & 0.85 \\
$\mathrm{AK}(\mathrm{mg} / \mathrm{kg})$ & Exponential & 0.1229 & 0.3658 & $33.6 \%$ & 252.47 & 0.60 \\
$\mathrm{Ga}(\mathrm{mg} / \mathrm{kg})$ & Exponential & 0.3100 & 0.9060 & $34.2 \%$ & 12.36 & 0.74 \\
\hline
\end{tabular}

Soil organic matter (OM); total nitrogen (TN); available phosphorus (AP); available potassium (AK); exchangeable calcium $(\mathrm{Ga})$ 

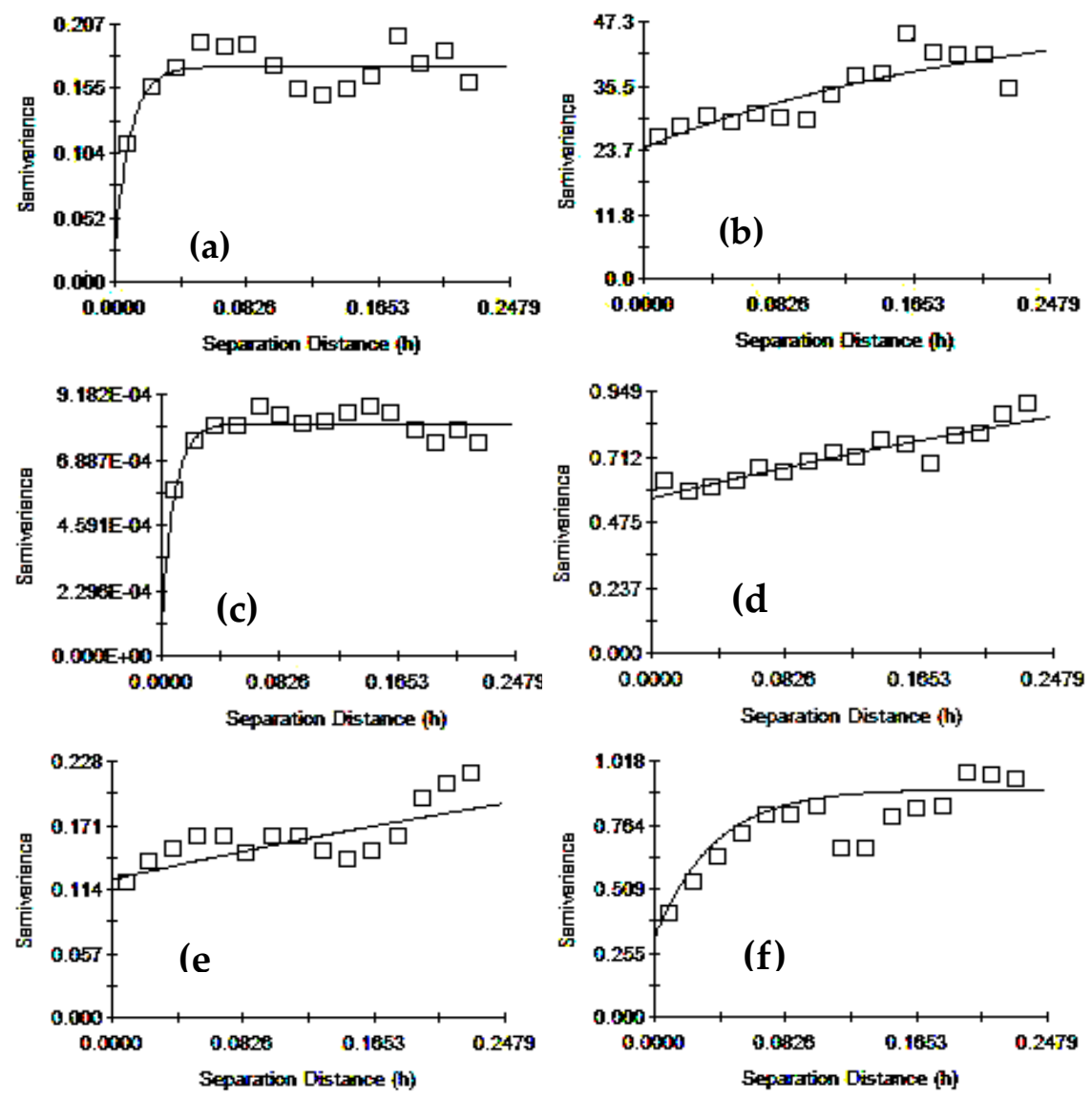

Fig.3. The semi-variograms of rubber yield and soil nutrients in the rubber plantation (a): rubber yield; (b): soil organic matter $(\mathrm{OM})$; (c): total nitrogen $(\mathrm{TN})$; (d): available phosphorus (AP); (e):available potassium (AK); (f) exchangeable calcium (Ga)

\subsection{Analysis the potential balance of soil nutrients in the rubber plantation}

Studying the balance of different soil nutrients in rubber plantation is important for making rational fertilizer application strategy, improving the effectiveness of fertilization and maintaining a high and stable rubber production. Based on previous studies of rubber plantation soil fertility condition by He et al. [15] and Wu et al. [16], the normal range for soil OM, TN, AP and AK nutrient were $20 \mathrm{~g} / \mathrm{kg}-25$ $\mathrm{g} / \mathrm{kg}, 0.08 \%-0.14 \%, 5 \mathrm{mg} / \mathrm{kg}-8 \mathrm{mg} / \mathrm{kg}, 40 \mathrm{mg} / \mathrm{kg}-60 \mathrm{mg} / \mathrm{kg}$, respectively and the threshold value of $\mathrm{Ga}$ was $25 \mathrm{mg} / \mathrm{kg}$. The classification of different soil properties in the study area were shown in Table 3. The results showed that the levels of soil organic matter (OM) and total nitrogen (TN) nutrient in the studied rubber plantation were very low. For available phosphorus (AP) and available potassium (AK), only $26.30 \%$ and $38.53 \%$ of samples, respectively, were among in the normal range; in other words, the soil available phosphorus and available potassium nutrient were too less or too much in most areas of rubber plantation. The soil in the studied area was rich in exchangeable calcium (Ga) with $81.96 \%$ samples greater than the threshold value $(25 \mathrm{mg} / \mathrm{kg})$.

Table 3. The classification of soil properties in rubber plantation of Guangba Farm

\begin{tabular}{ccccc}
\hline \multicolumn{2}{c}{ Soil properties } & Low & Normal & High \\
\hline organic matter & Grading standard & $<20 \mathrm{~g} / \mathrm{kg}$ & $20-25 \mathrm{~g} / \mathrm{kg}$ & $>25 \mathrm{~g} / \mathrm{kg}$ \\
\cline { 2 - 5 }
\end{tabular}




\begin{tabular}{ccccc}
\hline \multirow{2}{*}{$(\mathrm{OM})$} & Number & 302 & 18 & 7 \\
\cline { 2 - 5 } & Percentage (\%) & $92.35 \%$ & $5.50 \%$ & $2.14 \%$ \\
\hline \multirow{3}{*}{ total nitrogen (TN) } & Grading standard & $<0.08 \%$ & $0.08-0.14 \%$ & $>0.14 \%$ \\
\cline { 2 - 5 } & Number & 223 & 97 & 7 \\
\cline { 2 - 5 } & Percentage (\%) & $68.20 \%$ & $29.66 \%$ & $2.14 \%$ \\
\hline \multirow{2}{*}{$\begin{array}{c}\text { available } \\
\text { phosphorus (AP) }\end{array}$} & Grading standard & $<5 \mathrm{mg} / \mathrm{kg}$ & $5-8 \mathrm{mg} / \mathrm{kg}$ & $>8 \mathrm{mg} / \mathrm{kg}$ \\
\cline { 2 - 5 } & Number & 90 & 86 & 151 \\
\cline { 2 - 5 } & Percentage $(\%)$ & $27.52 \%$ & $26.30 \%$ & $46.18 \%$ \\
\hline \multirow{2}{*}{$\begin{array}{c}\text { available } \\
\text { potassium (AK) }\end{array}$} & Grading standard & $<40 \mathrm{mg} / \mathrm{kg}$ & $40-60 \mathrm{mg} / \mathrm{kg}$ & $>60 \mathrm{mg} / \mathrm{kg}$ \\
\cline { 2 - 5 } & Number & 122 & 126 & 79 \\
\cline { 2 - 5 } & Percentage (\%) & $37.31 \%$ & $38.53 \%$ & $24.16 \%$ \\
\hline \multirow{2}{*}{$\begin{array}{c}\text { exchangeable } \\
\text { calcium (Ga) }\end{array}$} & Grading standard & $<25 \mathrm{mg} / \mathrm{kg}$ & $\geqslant 25 \mathrm{mg} / \mathrm{kg}$ & $/$ \\
\cline { 2 - 5 } & Number & 59 & 268 & $/$ \\
\cline { 2 - 5 } & Percentage $(\%)$ & $18.04 \%$ & $81.96 \%$ & $/$ \\
\hline
\end{tabular}

\section{Discussion}

In this study, rubber yield and soil nutrients shown obvious spatial dependence in the rubber plantation. The relationship between rubber yield and five soil nutrients were given in Table 4. Rubber yield were strongly related with soil available phosphorus (AP), available potassium (AK) and exchangeable calcium $(\mathrm{Ga})$ at significance level of 0.01 . But no relationships were found between yield and soil organic matter (OM), total nitrogen (TN), which was contradictive with the previous study by An et al. [17], it could mainly because the serious lack of soil OM and N. Luo et al. [18] pointed out that the leaf nutrient content was directly related to the nutrient condition of rubber tree and the latex yield, although soil was the source of rubber tree nutrient. The immobilization capability of soil and the absorption capacity of rubber tree may lead to less $\mathrm{OM}$ and $\mathrm{TN}$ content in soil but more in rubber tree. Therefore, comprehensive consideration of the soil nutrient and leaf nutrient is essential to know the factors affecting rubber yield.

Table 4. The relationship between rubber yield and soil nutrients

\begin{tabular}{lllllll}
\hline & $\mathrm{OM}$ & $\mathrm{TN}$ & $\mathrm{AP}$ & $\mathrm{AK}$ & $\mathrm{Ga}$ & Yield \\
\hline $\mathrm{OM}(\mathrm{g} / \mathrm{kg})$ & 1 & $0.763^{* *}$ & 0.048 & $0.260^{* *}$ & $0.223^{* *}$ & 0.004 \\
$\mathrm{TN}(\%)$ & $0.763^{* *}$ & 1 & 0.042 & $0.205^{* *}$ & $0.197 * *$ & 0.001 \\
$\mathrm{AP}(\mathrm{mg} / \mathrm{kg})$ & 0.048 & 0.042 & 1 & $0.130^{*}$ & 0.030 & $-0.154^{* *}$ \\
$\mathrm{AK}(\mathrm{mg} / \mathrm{kg})$ & $0.260^{* *}$ & $0.205^{* *}$ & $0.130^{*}$ & 1 & $0.543^{* *}$ & $-0.176^{* *}$ \\
$\mathrm{Ga}(\mathrm{mg} / \mathrm{kg})$ & $0.223^{* *}$ & $0.197^{* *}$ & 0.030 & $0.543^{* *}$ & 1 & $-0.185^{* *}$ \\
$\mathrm{Yield}\left(\mathrm{kg} / \mathrm{hm}^{2}\right)$ & -0.210 & 0.001 & $-0.154^{* *}$ & $-0.176^{* *}$ & $-0.185^{* *}$ & 1 \\
\hline
\end{tabular}

Note: * Significant at the 0.05 level; ** Significant at the 0.01 level.

Soil organic matter (OM); total nitrogen (TN); available phosphorus (AP); available potassium (AK); exchangeable calcium $(\mathrm{Ga})$ 


\section{Conclusion}

Studying the rule of spatial variability of rubber yield and soil nutrients and their spatial distribution characters are important to formulate a suitable fertilization strategy in rubber plantation. The spatial distribution characters of rubber yield and five soil nutrients, including OM, TN, AP, AK, Ga were studied by using traditional analysis method and geo-statistics analysis method in this paper.

The average value of rubber yield was $3.55 \mathrm{~kg} / \mathrm{hm}^{2}$ with moderate variability. For the five soil nutrients, the average values of OM, TN, AP, AK and Ga were $11.65 \mathrm{~g} / \mathrm{kg}, 0.07 \%, 16.23 \mathrm{mg} / \mathrm{kg}, 49.65$ $\mathrm{mg} / \mathrm{kg}$ and $84.44 \mathrm{mg} / \mathrm{kg}$, respectively. Soil OM, TN, AK and Ga had moderate variability but P had strong variability. Through the analysis of semi-variograms, rubber yield and soil TN nutrient had strong spatial dependence; rubber yield and soil OM, AP, AK and Ga had moderate spatial dependence. Based on the previous studies of standard range of soil nutrients, OM and TN nutrient were very low in the studied rubber plantation of Guangba Farm. Therefore, more nitrogen fertilizer should be applied in the rubber plantation in Guangba Farm in future.

Funding Information. This work was supported by National Natural Science Foundation of China (41801352), Natural Science Foundation of Hainan Province, China (20164179, 2016CXTD015), Youth Foundation of Director of Institute of Remote Sensing and Digital Earth, Chinese Academy of Sciences, China (ZZCEODE2015HT015), the Agricultural Science and Technology Innovation of Sanya (2015KJ04), the Technology Research, Development and Promotion Program of Hainan Province, China (ZDXM2015102), the Hainan Provincial Department of Science and Technology under Grant ( ZDKJ2016021).

\section{References}

1. Yang, Z.J., Wei, J.S., He, P., Wu, B.S., Wu, M.: Spatial variance of potassium in rubber plantation soil in Danzhou city of Hainan province. Journal of northwest forestry university, 25(5), 41-44 (2010).

2. Yang, Z.J. Study on time-space variation characters of soil nutrients in different scales of rubber plantation. Haikou: Hainan University, 2010.

3. Qin, H. D., Wu, B. S., Wu, M., Wei, J. S., He, P., Wang, D. P., Gao, L.: Spatial Variability and Regionalized Management of Soil Phosphorus Nutrients in the Rubber Plantation in Qiongzhong County. Chinese Journal of Tropical Crops, 35(2), 369-374 (2014).

4. Li, X. Q., Yu, L. X., Li, C. L., Lu, W. K.: Spatial distribution characteristic of soil nutrients in rubber plantation of Dongfeng Farm of Yunnan province. Southwest China Journal of Agricultural Sciences, 28(1):292-298 (2015).

5. Gao, L., Wei, J. S., Wu, B. S., He, P., Wu, M.: Characteristics of Spatial Variability of Soil Nutrients in Rubber Plantation in Ledong Country, Hainan. Chinese Journal of Tropical Crops, 35(11):2115-2120 (2014).

6. Li, G. Y., Wang, Q. B., Li, Y. Y., Zhou, S. X., Yu, H. Y.: A review of influencing factors on latex yield of Hevea brasiliensis. Chinese Journal of Ecology, 33(2), 510-517 (2014).

7. Gao, X.Z., Hu, K. L., Guo, Y., Li, B. G., Ma, Y. T., Du, S., Wang, Y. H.: Spatial variability of soil nutrients and crop yield and site-specific fertilizer management. Scientia Agriculture Sinica, 35(6):660-666 (2002).

8. Yang, Y. L., Tian, C. Y., Sheng, J. D., Wen, Q. K.: A study on relationship between spatial variability of soil 
solute salt and the cotton growth. Arid Land Geography, 4, 329-335 (2002).

9. Yang, Y. L., Sheng, J. D., Tian, C. Y., Wen, Q. K.: A study on relationship between the spatial variability of saline anthropogenic alluvial soil available nitrogen, phosphorous, potassium and cotton growth $[\mathrm{J}]$. Scientia Agriculture Sinica, 36(5), 542-547 (2003).

10. Cui, B.: The study of temporal and spatial variation of soil nutrient and winter wheat growth information on field scale. Shanxi: Shanxi Agricultural University, (2013).

11. Nelson, D.W., Sommers, L.E.: A rapid and accurate method for estimating organic carbon in soil. Proc. Indiana Acad. Sci. 84, 456-462 (1975).

12. Lu, R. K.: Methods of chemical analysis of agriculture soil. China agricultural science and technology press, (2000).

13. Ding, X.D.: Comparisons among the methods of handling outliers. Computing techniques for geophysical and geochemical exploration 18(1), $71-77$ (1996). (in Chinese with English Abstract)

14. Wang, Z. Q.: Geo-statistics and Application in Ecology: first edition. Beijing: Science Press, 35-149 (1999). (In Chinese)

15. He, X. D., Lu, X. Z., Wu, X. P.: Study on soil fertility and utilization of soil fertility in Hainan island. Tropical agricultural science, 40-48 (1991).

16. Wu, M., He, P., Wei, J. S.: Integrated evaluation of soil fertility for rubber plantation in Hainan province. Chinese Soil and Fertilizer, 2, 1-5(2009).

17. An, F., Xie, G. S., Jiang, J. S., Lin, W. F., Xie, Y. F., Pan, Y. W., Deng, J. M., He, J., Sheng, D., Tan, S.M., Yin, Z. M.: Nutrient conditions of rubber plantations and their relationship with latex yield under stimulated tapping system in Xishuangbanna. Chinese Journal of Tropical Crops, 26(3):1-6 (2005).

18. Luo, W., Lin, Z. M., Cha, Z. Z.: The development course and trend of nutrition diagnosis of soil nutrition in rubber tree in China. The first national soil testing and fertilizer technology seminar, July 9-10, Hohhot (2006). 